\title{
Control System Design: Think Broad and Be Inquisitive
}

Krzysztof Malinowski

Warsaw University of Technology, Faculty of Electronics and Information Technology, ul. Nowowiejska 15/19, 00-665 Warszawa

Abstract: In this paper two examples, of a different nature, are presented to demonstrate, basing upon the author's experience from the past, that the control engineer facing a design problem must think in broad terms, be careful when design supporting tools are used and do not neglect theory related to the considered design problem.

Keywords: control system, optimization

\section{Introduction}

This paper has been written basing upon the author's experience from the remote past. About forty years ago, just after obtaining the DSc degree (habilitation) from the Warsaw University of Technology, I have become involved, as a senior visiting fellow of SERC (Science Engineering Research Council) at UMIST, a leading institute of technology in England, in a number of research projects. The main involvement was in special projects concerned with parallel and/or decentralized/hierarchical simulation of coolant systems of pressurized water nuclear reactors and with optimization of the complex systems. Apart of those main research directions I have also become involved, as a consultant, in design of two regulatory control systems. It never has occurred to me, until now, that my contribution to solving these two design problems was really worth to write about. It just happened a few weeks ago that I have been talking about these problems with my former PhD student, Cezary Zieliński, now a senior Professor at the Warsaw University of Technology and my successor as the head of the Control Systems Division at the Faculty of Electronics and Information Technology of WUT. He had found the story interesting and of long lasting value and then has encouraged me to write about it. So be it; I hope that the reader will enjoy reading this short text.

The main purpose of this paper is to illustrate, through the two following examples, that a design engineer should always be inquisitive, think in broad terms and both know and be ready to use the theory related to the design problem under consideration - no matter what supporting software she or he has at the disposal.

Autor korespondujący:

Krzysztof Malinowski, k.malinowski@ia.pw.edu.pl

Artykuł recenzowany

nadesłany 28.04.2020 r., przyjęty do druku 22.06.2020 r.
The first design problem was related to computation of a state feedback stabilizing controller for large - for that time - linear system with sixteen state variables, by solving well defined linear-quadratic optimization problem. Actually, the final objective was to design an optimal control feedback using the state feedback controller in which the state estimates from the optimal observer (Bucy-Kalman Filter) were to be plugged into the state feedback control law. Yet it happened, somewhat surprisingly, that it was the design of the state feedback matrix that for a considerable time became a major problem. In this case good grasp of theory proved to offer a solution, to find deficiency of a specialized routine from then current version of the NAG (Numerical Algorithms Group ) library of numerical routines - which library, first released in 1971, was ten years later considered to be the top numerical library.

The second example presents a real life regulatory control design problem that, surprisingly enough, for a considerable time denied all efforts spent on finding a satisfactory controller for the considered important MIMO plant. The solution, almost trivial after being found and explained, has lied beyond the regulatory controller design itself; it required structural changes as far as the set of the controlled variables was concerned. In this case a broader view of the problem, above the controller design itself, proved to be essential.

Cited references to the text below are few; the examples considered do not seem to require more.

\section{Design of stabilizing controller through solution of the time-invariant infinite-horizon linear-quadratic optimal control problem}

The objective of the case study design, as considered in this section, was to find satisfactory stabilizing controller for a linear system,

$$
\dot{x}(t)=A x(t)+B u(t)
$$

with $x(t) \in R^{16}, u(t) \in R^{m}$ and given time-invariant matrices $A$ and $B$ of dimension, respectively, $16 \times 16$ and $16 \times m$. 
The actual value of $m$, where $\operatorname{dim}(m) \leq \operatorname{dim}(x)$, is not relevant for further considerations.

The task was to compute the state-feedback controller

$$
u(t)=-F x(t)
$$

with time-invariant gain feedback matrix, such that the closed-loop system

$$
\dot{x}(t)=(A-B F) x(t)
$$

was asymptotically stable, with a reasonable placement of the closed-loop poles. The computation of the gain matrix $F$ was approached by solving the time-invariant infinite-horizon linear-quadratic optimal control problem (for convenience marked as the LQIH Problem), i.e. by minimizing the criterion

$$
\lim _{t_{1} \rightarrow+\infty} \int_{0}^{t_{1}}\left[x^{\mathrm{T}}(t) Q x(t)+u^{\mathrm{T}}(t) R u(t)\right] d t
$$

where matrices, in this case design parameters, $Q$ and $R$ satisfied the conditions: $Q=Q^{\mathrm{T}}>0, R=R^{\mathrm{T}}>0$, i.e. both $Q$ and $R$ were symmetric positive-definite matrices.

It should be observed that it would have been sufficient to assume that $Q=Q^{\mathrm{T}} \geq 0$ (i.e. $Q$ nonnegative-definite) with $Q=D^{\mathrm{T}} Q_{1} D, \quad Q_{1}=Q_{1}^{\mathrm{T}}, \quad Q_{1}>0$ and with system (1) being observable (or just reconstructible) through the time-invariant "output" equation $z(t)=D x(t)$. Such generalization, however, is not needed in most real-life cases, in which $Q$ as the design matrix parameter is defined as positive definite and, usually, just as a diagonal matrix with positive entries on the diagonal. Similarly, $R$ is usually defined as a diagonal matrix with positive elements on the diagonal. So it has been in the case considered.

When, instead of $x(t)$, the only information available on-line is given by observing the measurement vector $y(t)$, where $y(t)=C x(t)$, providing for observability of the state, then the estimate $\hat{x}(t)$ may be plugged into the control law (2) instead of the actual state value $x(t)$. In fact, in case of white-noise type disturbances added to the right hand side of equation (1) and to the above observation equation $y(t)=C x(t)$, the steady-state Kalman-Bucy Filter, as an optimal observer, allows to compute the state estimate $\bar{x}(t)$, which - when used in (1) - provides for an optimal closed-loop control law (i.e. law minimizing criterion (4)).

Nevertheless, in this section we are concerned only with computation of the optimal gain matrix $\bar{F}$, to be used in control law (2). Assuming that the system (1) is controllable, the solution of the above LQIH Problem is given (see e.g. Kwakernak and Sivan 1972) as

$$
u(t)=-\bar{F} x(t),
$$

where

$$
\bar{F}=R^{-1} B^{\mathrm{T}} \bar{P}
$$

and where a symmetric matrix $\bar{P}$, positive-definite under the assumptions made above about system (1) being controllable and $Q=Q^{\mathrm{T}}>0$, is the single solution of the matrix algebraic Riccati equation

$$
Q-P B R^{-1} B^{\mathrm{T}} P+A^{\mathrm{T}} P+P A=\mathbf{0}
$$

where $\mathbf{0}$ is a matrix with all entries equal to 0 . (In case of relaxed assumptions of nonnegative-definite symmetric matrix $Q$, i.e. $Q=Q^{\mathrm{T}} \geq 0$ with $Q=D^{\mathrm{T}} Q_{1} D, \quad Q_{1}=Q_{1}^{\mathrm{T}}, \quad Q_{1}>0$, system (1) being just stabilizable and, with the "output" $z(t)=D x(t)$, being reconstructible, matrix $\bar{P}$ may be proved to be single nonnegative-definite solution of eq. (7).
Feedback law defined in eqn.(5), with $F=\bar{F}, \bar{F}$ given by eq. (6) with $\bar{P}$ being the positive-definite solution of eq. (7), provides for asymptotic stability of the closed-loop system

$$
\dot{x}(t)=(A-B \bar{F}) x(t)
$$

with poles of system (8) placed in the left hand (negative real parts) sub-plane of the complex numbers. The pole locations depend in a transparent way on the design parameters, i.e. on the elements of, in most cases diagonal, weight matrices $Q$ and $R$.

In the case under consideration the matrix equation (7) with $\operatorname{dim}(x(t)=16)$ defined a set of 256 nonlinear equations. Due to matrices $Q, R$ and $P$ being symmetric the matrix on the left hand side of eq. (7) was also symmetric and so the number of independent nonlinear equations to be solved in order to compute $\bar{P}$ was equal to 136 (120 off-diagonal entries plus 16 entries on the diagonal). The remaining equations could be used, and actually were used, to check whether the computed matrix $\bar{P}$ did satisfy all of them.

For computing a solution of this set of 136 nonlinear equations (which forty years ago represented quite large set of nonlinear equations to be dealt with) the appropriate NAG library routine was used. The routine returned matrix $\tilde{P}$ as a solution of the matrix Riccati equation (7). This matrix has been then used for computing, according to eqn. (6), the feedback gain matrix $\tilde{F}=R^{-1} B^{\mathrm{T}} \tilde{P}$ and for setting up the controller

$$
u(t)=-\tilde{F} x(t),
$$

Then, if I well remember, an observer, working properly on its own, was developed to compute the estimates $\hat{x}(t)$ of $x(t)$ for $t>0$. Finally, the closed-loop system

$$
\dot{x}(t)=A x(t)-B \tilde{F} \hat{x}(t)
$$

was tested through the computer simulation. Against all expectations this system, quite unfortunately, appeared to be very unstable! Why?

The first guess regarding the source of this instability was that something had gone wrong as far as the coupling of the observer and the controller was concerned. Yet, the observer was, on itself, working very well, proving in fact that the system under control was beyond any doubt observable.

The simulation was then used to check the behavior of the closed-loop system with full state feedback

$$
\dot{x}(t)=(A-B \tilde{F}) x(t)
$$

System (11) appeared to be unstable!

All equations and data were checked and rechecked; nothing was achieved.

It was postulated then that, perhaps, system (1) was uncontrollable - against all expectations and relation to physical properties and behavior of the system that eq. (1) did in fact represented - with an uncontrollable mode (or modes) being unstable. This issue has been investigated and it was confirmed that system (1) was controllable. So, if everything was properly set up, why the closed-loop system (11) was unstable?

Only after considerable time it has been suggested that, perhaps, the library routine for solving eq. (7) was not returning the required solution, i.e. a positive-definite matrix $\bar{P}$ satisfying eq. (7). As a first reaction to this postulate the majority of the design engineers involved - and there were quite many at this stage - have been adamant; it seemed impossible to them that a routine from the best library, used with success in many cases before, could return an improper solution. Then, some engineers 
decided to explore the fact that, according to linear-quadratic optimal control problem, matrix $\bar{P}$ was originally defined as the limit value of the solution of differential Riccati dynamic equation, for $t<t_{1}$ and $P\left(t_{1}\right)=P_{1}, P_{1}=P_{1}^{T} \geq 0$,

$-\dot{P}(t)=Q-P(t) B R^{-1} B^{\mathrm{T}} P(t)+A^{\mathrm{T}} P(t)+P(t) A$

Let us denote the solution as $P_{t_{1}}(t)$, with $t<t_{1}$ Then, for any fixed real number $t \in R$, there exists, under the assumptions made, an actual limit $\bar{P}$ matrix when $t_{1} \rightarrow+\infty$, it can be computed as

$$
\bar{P}=\lim _{t_{1} \rightarrow+\infty} P_{t_{1}}(t)
$$

where $P_{t_{1}}(t)$ is symmetric and nonnegative definite, and so $\bar{P}$ is a nonnegative-definite solution of eq. $(7) . \bar{P}$ can also be obtained through solving the set of differential equations (12) (in the considered case 136 equations) backwards in time, assuming that $P\left(t_{1}\right)=P_{1}$ where $P_{1}$ is any nonnegative-definite symmetric matrix; then, given fixed $t_{1}$, seeking a limit

$$
\bar{P}=\lim _{t \rightarrow-\infty} P(t)
$$

In the case considered, due to controllability of (1) and due to matrix $Q$ being positive-definite, $\bar{P}$ should be positive-definite and the matrix obtained from eq. (13), as well as, more effectively as far as the computing effort was required, from eq. (14), was indeed positive definite. In fact $\bar{P}$ appeared to be largely different from $\tilde{P}$.

Matrix $\bar{P}$ obtained in the way described above, from eq. (13) or from eq. (14), is the sought-after nonnegative-definite (in our case positive-definite) matrix solution of the algebraic Riccati equation (7), which, when used in eq. (6) to define gain matrix $\bar{F}$, according to theory, provides asymptotically stable (in fact exponentially stable) closed-loop system

$$
\dot{x}(t)=(A-B \bar{F}) x(t)
$$

Now, the method presented above, using formula (13) or (14) to compute $\bar{P}$ was, and for large dimension of state vector $x$ still is, time consuming. Thus another method was and is up to now most often applied: $\bar{P}$ is computed by solving the nonlinear algebraic Riccati equation (7), i.e. the set of nonlinear algebraic equations, using, in most cases, Newton method, or a similar one. In such case, however, it appears that there might exist a possibility to find other than $\bar{P}$ solution of eq. (8), a solution that is not positive-definite or even nonnegative-definite. Using such solution, say $\breve{P}$, in equation (6) may very well result in the closed-loop system $\dot{x}(t)=(A-B \bar{F}) x(t)$

with

$$
\breve{F}=R^{-1} B^{\mathrm{T}} \breve{P}
$$

being unstable. This was, in fact, exactly what has happened in the considered case and which was due to the fact that well regarded library routine, providing proper solutions of algebraic matrix Riccati equation in many other cases, had in this case failed. It was only after a considerable effort spent on examining this problem that, due to understanding of the theory concerning LQIH, this failure was detected and the reason of it has been understood, and then the required proper solution computed.

The reader, interested in deeper insight into the theory of linear-quadratic problem as a tool for closed-loop control design may consult many excellent texts. One, especially worth mentioning, is the book "Linear Optimal Control Systems" by H. Kwakernaak and R. Sivan (Wiley-Interscience, 1972).

The lesson that can be drawn from this example is that even when using best possible software tool, e.g. a library routine supposed of returning us a solution of the actually considered problem, the designer should always be careful and know what this routine is doing and be able to detect and understand an eventual routine failure, and - if such failure does indeed happen - to be able to find a solution to the problem.

\section{Regulator design problem for natural gas processing and transporting facility}

The second example, or a case study, is of a different nature; not directly related to a particular design procedure but to a much broader issue concerned with the controller design.

One of the largest firms procuring crude oil and natural gas, transporting those media and then processing them in the company refineries, reported the following problem concerning transportation of the natural gas through the undersea pipeline, asking several research institutions for a solution. The problem was as follows.

At one of the sites in North Africa, belonging to this firm - call it firm TT - and situated close to the southern shore of the Mediterranean Sea, the well was established providing large quantities of natural gas with a residue of crude. The well was then to be connected to large tanks as shown in fig. 1, the purpose of those tanks being to separate the gas, coming from the well at the fluctuating pressure and quantity, from the residue crude and to make this gas ready for being pumped into the undersee pipe of a large dimension and capacity, transporting the gas to the recipient station in Europe. Three separator tanks were bought and connected to a large pump via much smaller header tank. Pump operation allowed for changing the pump rotational speed and the objective of the regulation was to provide for a desired constant pressure of gas at the outlet of the pump. Maintaining constant pressure at the pump outlet, i.e. the inlet to the undersea pipe, was most important task required to allow for smooth gas transmission, without pressure waves and chocks, i.e. without flow disturbances in the pipe being induced by changes of the pump outlet pressure.

Now, each separator tank, referred to as the separator, in which the natural gas has been separated from the residue crude, was provided by its producer with two regulatory loops. The first, the main loop, was designed to stabilize the gas pressure within the tank by manipulating the valve at the tank gas outlet. The second loop was supposed to stabilize the level of crude at the bottom of the tank. Both this latter loop and its task were very simple and not relevant to the main tank purpose; they will not be taken into account further on and will not be depicted on the diagrams below.

The pump, provided by another manufacturer, together with the header tank, was also endowed with the main control loop: the controller being responsible for maintaining constant desired pressure at the outlet by manipulating the pump angular speed. Thus, the configuration of the considered plant was as depicted in fig. 1. As mentioned above, the auxiliary controllers, in particular those concerned with maintaining the desired levels of crude in separator tanks, are not shown in fig. 1 . The four main controlled variables were pressure levels in the separators, respectively $p_{1}, p_{2}, p_{3}$, and the pump outlet pressure $p_{\text {out }}$; the main controls, manipulated variables, were three valve settings $u_{1}, u_{2}, u_{3}$ and signal $u_{4}$ setting the pump rotational speed.

After all components of the system were put into place, with, as it seemed, properly tuned controllers (if I well remember the PID controllers) - each, however, tuned when taking into account the individual perspective - it has immediately appeared that the operation of the system as a whole was absolutely unacceptable. Namely, the pressure $p_{\text {out }}$ at the outlet of the pump and the inlet to the undersea pipe was rapidly changing 
in a significant way - the amplitude of changes was very large and this could not be accepted and allowed for.

So, then much time and effort were devoted to re-tune the controllers so as to eliminate those variations of $p_{\text {out }}$. It did not do much good. Then a design of a multiple-input - multiple-output $(\mathrm{MIMO})$ controller $(4 \times 4)$ was tried; this also did not result in any significant improvement of the system behavior. Several research groups were consulted and asked for help but the problem still seemed to be unsolvable, after being extensively investigated.

Yet, the solution was simple and, in fact, almost apparent, one could say: "lying on the table". In the book "Wielopoziomowe układy sterowania" by W. Findeisen, published in 1974 and then in the book "Control and Coordination in Hierarchical Systems" by W. Findeisen et al., published in 1980, it was shown that often much improved behavior of a system operating in steady-state is possible to be achieved by a clever choice of the controlled variables; such choice may even lead to self-optimizing operation of a plant at steady-state. The choice of a good set of control variables may depend on the overall system configuration and the joint constraints imposed on the system variables.
It was suggested then, after much effort was spent on tackling the regulator design problem, that a similar approach, namely changing the set of the controlled (regulated) variables, might also be helpful in achieving the improved dynamical behavior of the controlled system as a whole.

Indeed, consider what happens in case of the system depicted in fig. 1, with the components of this system endowed with their controllers introduced on an individual basis. The pressure and, therefore, the flow of gas and crude mixture from the well, may and does change rapidly (fluctuates). Each separator pressure controller reacts to these changes and by stabilizing gas pressure in the separator at the desired level, passes in fact the flow fluctuations to the small header tank at the inlet to a huge pump with large inertia associated with the angular speed. When the pressure in the header changes rapidly, which it must, the pump controller cannot cope by changing the speed of the pump - there is far too much inertia to allow for it. Therefore, as far as one insists on keeping the original set $p_{1}$, $p_{2}, p_{3}, p_{\text {out }}$ of the controlled variables and attempting regulation of those variables to their desired set-point values, respectively, $p_{1, \mathrm{~d}}, p_{2, \mathrm{~d}}, p_{3, \mathrm{~d}}$ and $p_{\text {out }, \mathrm{d}}$, there is no chance to maintain $p_{\text {out }}$ at the desired level under realistic operational conditions.

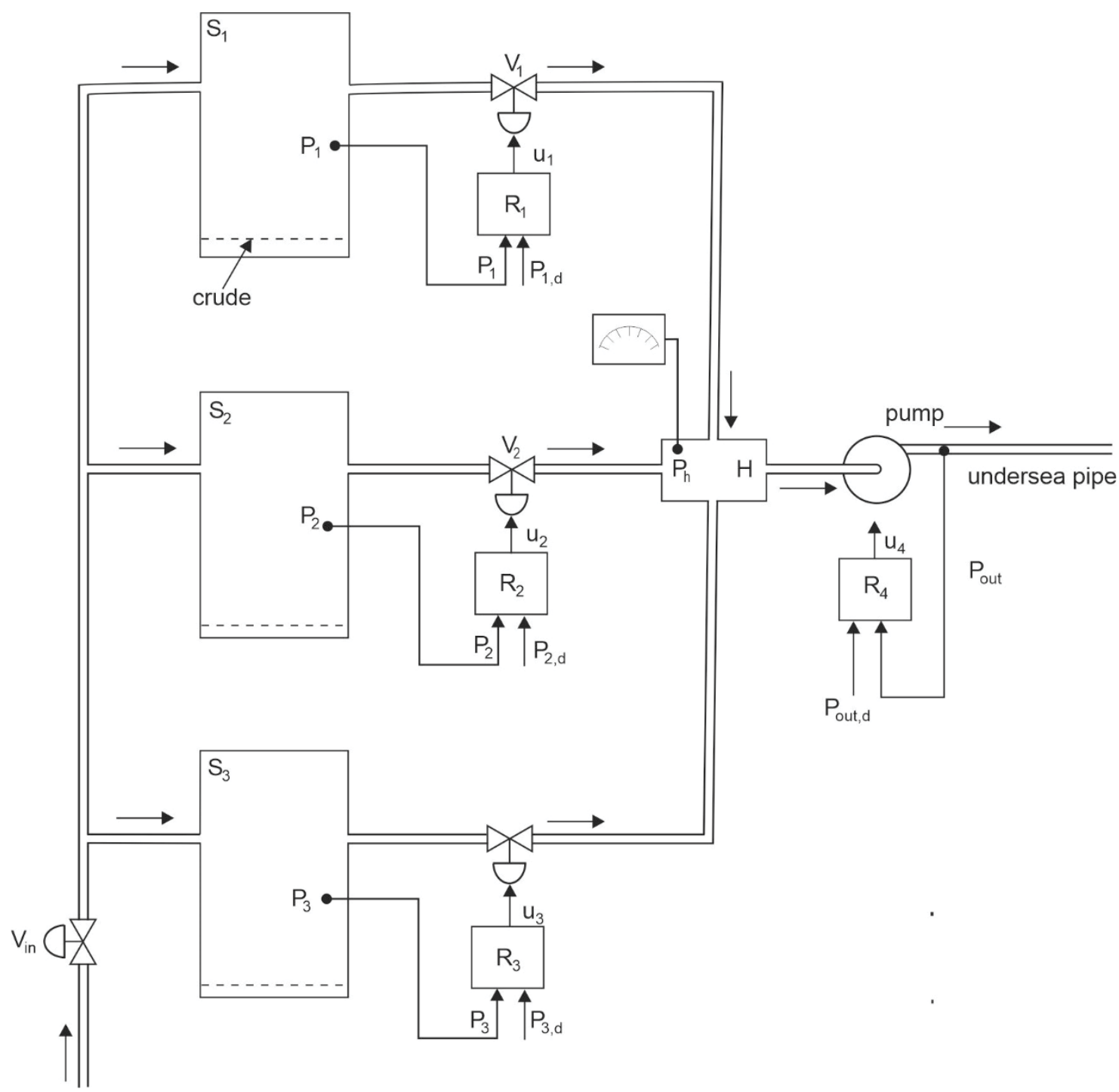

Fig. 1. Layout of the original control structure, case of four independent loops; only main elements of the plant are shown. Significant fast variations of header pressure $p_{h}$, unacceptable variations of $p_{\text {out }}$ at the pump outlet

Rys. 1. Schemat oryginalnej struktury układu sterowania, z czterema niezależnymi pętlami; pokazane są tylko główne elementy instalacji. Znaczące szybkie zmiany ciśnienia w kolektorze $p_{h}$, niedopuszczalne zmiany wydmuchu $p_{\text {out }}$ na wylocie pompy 


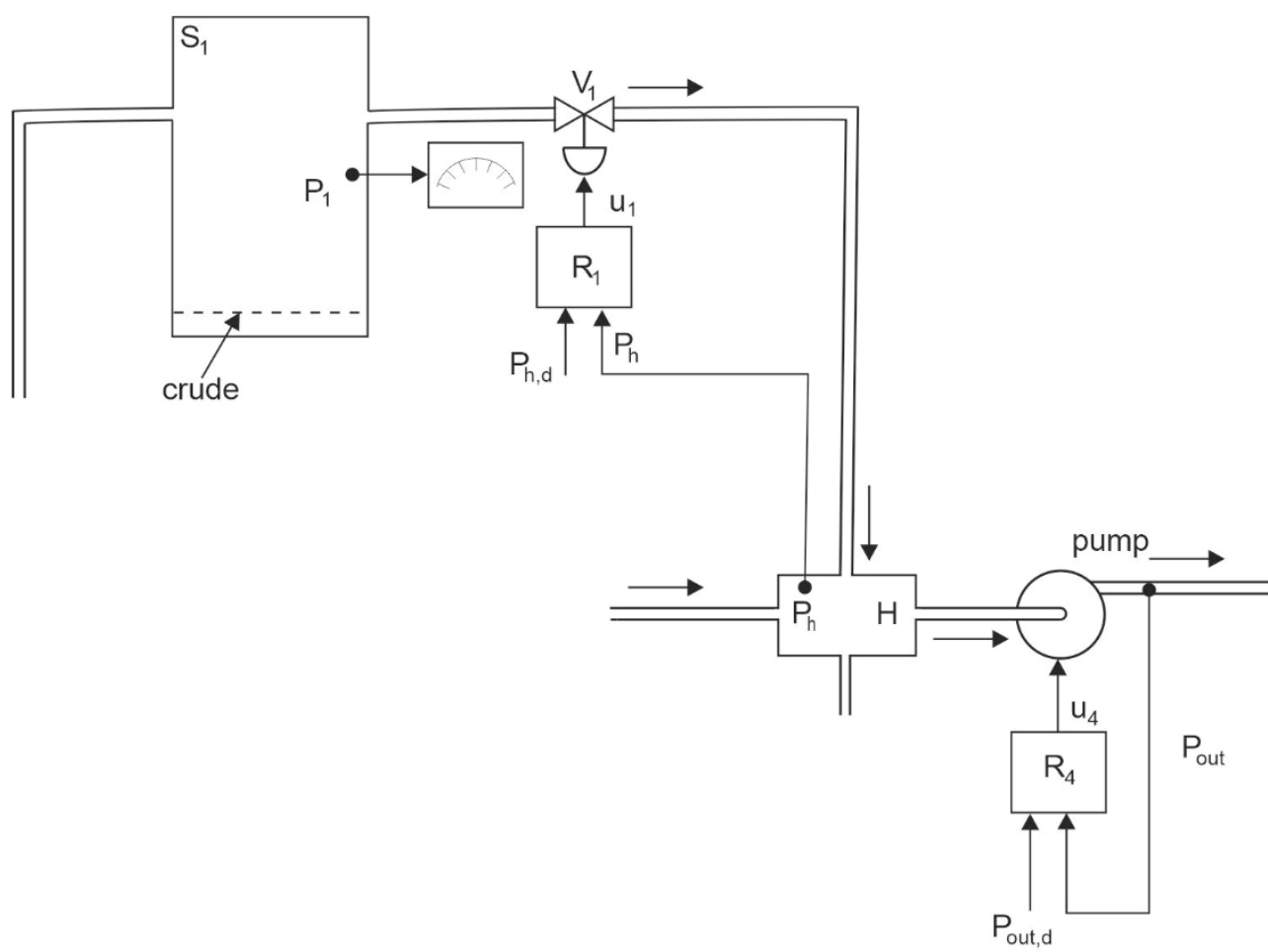

Fig. 2. New control structure (the elements not shown in fig. 1). New controlled variables: $p_{h}, p_{2}, p_{3}$ and pout. Variations in unregulated pressure $p_{1}$, small variations of header pressure $p_{h}$, acceptable changes of $p_{\text {out }}$

Rys. 2. Nowa struktura układu sterowania (elementy nie pokazane na rys. 1). Nowe zmienne kontrolowane: $p_{h}, p_{2}, p_{3}$ i $p_{o u t}$. Zmiany w nieregulowanym

ciśnieniu $p_{1}$, małe zmiany w ciśnieniu w głowicy $p_{h}$, dopuszczalne zmiany $p_{\text {out }}$

Now, in the considered case the really important controlled variable is actually $p_{\text {out }}$ as it is this pressure at the output of the pump that must be kept as being equal to the desired value $p_{\text {out }, d}$ and to fluctuate as little as possible so as to provide the best possible conditions for gas transmission under the sea. The remaining three controlled variables are not that important. Since it may be easily observed that a smooth pump operation depends upon the header pressure $p_{h}$ being constant one may remove one of the three separator pressures from the set of the controlled variables and introduce another controlled variable $-p_{h}$. One might remove, say, $p_{1}$ pressure and replace it with $p_{h}$. The fluctuations present in flow from the well will now be absorbed by separator no. 1 and will not be passed to the header. In addition to this the desired value of $p_{h}$, i.e. $p_{h, d}$, may be chosen such as to make the pump work at operating point of the best possible efficiency; thus, apart of creating the conditions for good regulation of $p$, one may also optimize the system operation at steady-state. The new configuration of the control structure is shown in fig. 2. There are of course some problems to take care of; in particular it may happen that the no longer controlled pressure $p_{1}$ in separator no. 1 could be getting too big; then it might be necessary to choke the flow from the well using valve $V_{i n}$, which action one usually would like to avoid at the basic regulation level as the flow going through this valve is a mixture of gas and crude, and since changing the position of $V_{i n}$ may disturb the operation of the well itself. Yet it is a fair price for being able to precisely control $p_{h}$ and optimize the value of $p_{h, d}$.

Actually it proved then quite easy to tune the controllers to provide satisfactory and power efficient operation of the considered plant with the new set $p_{h}, p_{2}, p_{3}, p_{\text {out }}$ of the controlled variables.

Therefore in order to solve the problem, to meet the requirements set by firm TT, it was only necessary to think in broader terms, to be not "enslaved" by the given set of the controlled variables. The truth that changing the set of the controlled variables may be the best solution to eliminate the dysfunctions of a regulatory controller is often lost on the specialists in regulatory control design.

\section{Conclusions}

The conclusions that can be drawn from the above examples were already presented in detail. In general terms they are: when facing a control design problem think broad, use available support tools with care and try to understand in all detail the theory relevant to your problem. This general conclusion most likely applies to all engineering design problems, not only to control design.

\section{References}

1. Findeisen W., Wielopoziomowe uktady sterowania [Multilevel Control Systems]. PWN, Warsaw 1974. German translation: Hierarchische Steureungssysteme. Verlag technik, Berlin 1977.

2. Findeisen W., Bailey F.N., Brdyś M., Malinowski K., Tatjewski P., Woźniak A., Control and Coordination in Hierarchical Systems. John Wiley \& Sons, Wiley Interscience Publication 1980.

3. Kwakernaak H., Sivan R., Linear Optimal Control Systems. John Wiley \& Sons, Wiley-Interscience 1972. 


\section{Projektowanie systemu sterowania: myśl nieszablonowo i bądź dociekliwy}

Streszczenie: W niniejszym artykule przedstawiono dwa przykłady o różnym charakterze, dla wykazania, w oparciu o doświadczenie autora, że inżynier systemów sterowania napotykający problem projektowy musi myśleć nieszablonowo, stosować roztropnie narzędzia wspomagające projektowanie i nie może zaniedbywać teorii związanej z rozważanym problemem projektowym.

Słowa kluczowe: system sterowania, optymalizacja

prof. dr hab. inż. czł. rzecz. PAN Krzysztof Malinowski

k.malinowski@ia.pw.edu.p.

ORCID: 0000-0002-7655-2050

Zainteresowania naukowe skupiają się wokół informatyki, automatyki, robotyki oraz układów regulacji (hierarchiczne układy sterowania). Członek korespondent krajowy Polskiej Akademii Nauk od 1998 r., członek rzeczywisty tej instytucji od 2016 r. Jest również członkiem

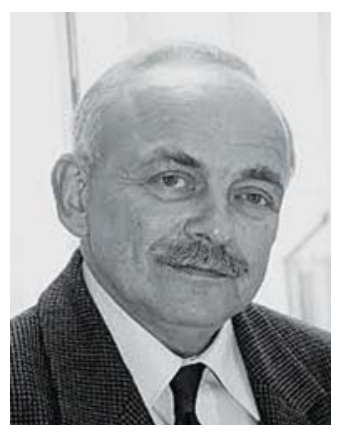

Warszawskiego Towarzystwa Naukowego

Pracownik Wydziału Elektroniki i Technik Informacyjnych Instytutu Automatyki i Informatyki Stosowanej na Politechnice Warszawskiej, oraz Naukowej i Akademickiej Sieci Komputerowej - Państwowego Instytutu Badawczego. 